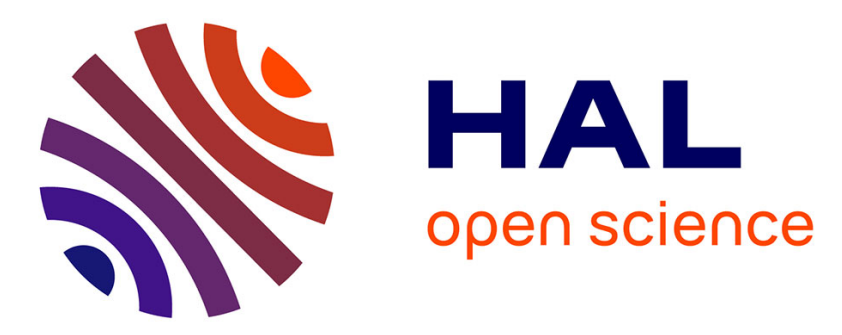

\title{
Use of thermogravimetry and thermodynamic calculations for specifying chromium diffusion occurring in alloys containing chromium carbides during high temperature oxidation
}

Patrice Berthod, Elodie Conrath

\section{To cite this version:}

Patrice Berthod, Elodie Conrath. Use of thermogravimetry and thermodynamic calculations for specifying chromium diffusion occurring in alloys containing chromium carbides during high temperature oxidation. Materials Chemistry and Physics, 2015, 165, pp.79-86. 10.1016/j.matchemphys.2015.08.057 . hal-02902137

\section{HAL Id: hal-02902137 \\ https://hal.science/hal-02902137}

Submitted on 17 Jul 2020

HAL is a multi-disciplinary open access archive for the deposit and dissemination of scientific research documents, whether they are published or not. The documents may come from teaching and research institutions in France or abroad, or from public or private research centers.
L'archive ouverte pluridisciplinaire HAL, est destinée au dépôt et à la diffusion de documents scientifiques de niveau recherche, publiés ou non, émanant des établissements d'enseignement et de recherche français ou étrangers, des laboratoires publics ou privés. 


\title{
Use of thermogravimetry and thermodynamic calculations for specifying chromium diffusion occurring in alloys containing chromium carbides during high temperature oxidation
}

Patrice Berthod and Elodie Conrath

\author{
Institut Jean Lamour \\ Department $N^{\circ}$ 2: Chemistry and Physic of Solids and Surfaces \\ Team "Surface and interface, chemical reactivity of materials" \\ Faculty of Sciences and Technologies, University of Lorraine \\ B.P. 70239, 54506 Vandoeuvre-lès-Nancy - France
}

Corresponding author's e-mail: pberthodcentralelille1987@orange.fr

Corresponding author's phone: (33)3 83684666 and fax number: (33)3 83684611

Post-print version of the article Materials Chemistry and Physics 165 (2015) 79-86. http://dx.doi.org/10.1016/j.matchemphys.2015.08.057

\begin{abstract}
The chromium diffusion is of great importance for the high temperature oxidation behavior of the chromia-forming carbides-strengthened superalloys. These ones are rich in this element for insuring their resistance against hot corrosion by constitute and maintain a continuous external scale of chromia protecting them. Knowing the chromium diffusion in such alloys is thus very useful for predicting the sustainability of their chromia-forming behavior. Since this Cr diffusion occurs through the external part of the alloy already affected by the previous steps of oxidation (decarburized subsurface) it is more accurate to specify this diffusion during the oxidation process itself. This was successfully carried out in this work in the case of a model chromiaforming nickel-based alloy containing chromium carbides, $\mathrm{Ni}$ (bal.)-25Cr-0.5C (in wt.\%), by combining the mass gain kinetic by oxidation specified by real-time thermogravimetry and the post-mortem determination of the $\mathrm{Cr}$ concentration profiles in subsurface. The values of $\mathrm{D}_{\mathrm{Cr}}$ thus obtained for 1000,1050 and $1100^{\circ} \mathrm{C}$ in the alloy subsurface are consistent with the values obtained in earlier works for similar alloy's chemical compositions.
\end{abstract}

Keywords: alloy (A); XRD (B); SEM (B); high temperature corrosion (C); kinetic parameters $(\mathrm{C})$

\section{Introduction}

Diffusion phenomena in metallic alloys at high temperature play very important role in many fields, from the elaboration of the alloys (e.g. powder metallurgy [1,2], mechanical alloying [3], joining \& welding [4], deposition of coatings [5] or heat treatments [6]) to the chemical behaviour in service. In the latter case there is notably the progress of oxidation which involves the diffusion of elements such as aluminium, 
chromium or silicon $[7,8]$. Al (respectively $\mathrm{Cr}$ or $\mathrm{Si}$ ) is usually present in superalloys $[9,10]$ in quantities sufficiently high to allow an alumina-forming (resp. chromiaforming or silica-forming) behaviour of the alloys when exposed to oxidant gases at high temperature. In the case of chromium, $20 \mathrm{wt} . \% \mathrm{Cr}$ in a nickel-based alloy and 30 wt.\% $\mathrm{Cr}$ in a cobalt-based alloy are generally considered as minimal contents. But another important property for an acceptable behaviour in oxidation at high temperature is the easiness of diffusion of the considered element - $\mathrm{Al}, \mathrm{Cr}$ or $\mathrm{Si}$ - towards the oxidation front for a sufficient supplying of the oxidation front in these elements to allow keeping a continuous protective scale of $\mathrm{Al}_{2} \mathrm{O}_{3}, \mathrm{Cr}_{2} \mathrm{O}_{3}$ and $\mathrm{SiO}_{2}$. Values of diffusion coefficients of $\mathrm{Al}, \mathrm{Cr}$ or $\mathrm{Si}$ are available about the diffusion of these elements in pure metals or simple solid solutions but their use in case of multi-phase alloys is generally not evident. Knowing the average diffusion coefficients mixing the effects of grain orientation, grain boundaries and intergranular second phases is though important to estimate the risk of catastrophic oxidation start.

In fact, the thermogravimetry tests in hot oxidant gases, the primary role of which is to evaluate the oxidation resistance of the alloys at high temperature, can be on the other hand also used to characterize the diffusion of the most oxidable species existing in the alloys [11]. Indeed the association of the measurements of oxidation-induced mass gain by thermo-balance and of the concentration profiles acquired in the sub-surface of the oxidized samples may allow deducing global diffusion coefficients $[11,12]$.

In the present study the diffusion of chromium was specified by this method for a cast polycrystalline alloy based on nickel and containing $25 \mathrm{wt} . \% \mathrm{Cr}$ for an average density of intergranular chromium carbides (given by the presence of $0.5 \mathrm{wt} . \% \mathrm{C}$ ), this for three levels of high temperature: 1000,1050 and $1100^{\circ} \mathrm{C}$.

\section{Material and methods}

\subsection{Elaboration of the alloy of the study}

An alloy, with as targeted composition $\mathrm{Ni}$ (bal.)-25Cr-0.5C (all contents in weight percent), was initially synthesized by foundry. Parts of pure nickel, pure chromium and graphite (Alfa Aesar, purity higher than 99.9 wt.\%) were weighed and placed together in the water-cooled copper crucible of a CELES furnace. They were heated by high frequency induction (about $110 \mathrm{kHz}$, voltage: 4000 Volts) under an inert 
atmosphere composed of 300 mbar of pure argon, in a chamber separated from the laboratory air by a silica tube. The molten alloy was maintained at about $1600^{\circ} \mathrm{C}$ during three minutes to be sure that the melt was completely homogenized and the power was then decreased with as consequence the solidification and the cooling of the alloy in contact with the metallic crucible.

After return to room temperature, the ingot, which was of a compact shape, was thereafter cut to get a part for the as-cast microstructure observations and control of the obtained chemical composition, and other parts for the preparation of samples (parallelepipeds of about $8 \mathrm{~mm} \times 8 \mathrm{~mm} \times 3 \mathrm{~mm}$ ) destined to be oxidized with measurement of their mass change and thereafter analyzed to specify the concentration profiles in their sub-surface.

\subsection{The oxidation tests}

Four parallelepipeds prepared by cutting of the ingot with a Buehler Delta Abrasimet metallographic saw were ground on their six faces with 1200-grit SiC papers. Additionally their edges and corners were smoothed by grinding them using the same papers. Four thermogravimetry tests were performed, all using a SETARAM TG92 thermo-balance under a flow of synthetic dry air $\left(80 \% \mathrm{~N}_{2}-20 \% \mathrm{O}_{2}\right)$, and composed of a heating phase at $+20 \mathrm{~K} / \mathrm{min}$, an isothermal stage at given high temperature $\mathrm{T}$ for a given duration $\Delta \mathrm{t}$, and a cooling phase at $-5 \mathrm{~K} / \mathrm{min}$. The three $\{\mathrm{T}, \Delta \mathrm{t}\}$ couples were: $\left\{1000^{\circ} \mathrm{C}, 46\right.$ hours $\},\left\{1050^{\circ} \mathrm{C}, 46\right.$ hours $\}$ and $\left\{1100^{\circ} \mathrm{C}, 46\right.$ hours $\}$. These tests led to mass gain files $\{\Delta \mathrm{m} / \mathrm{S}=\mathrm{f}(\mathrm{t})\}$, the end of the isothermal part of which was analysed to value the final mass gain rate $\mathrm{d}(\Delta \mathrm{m} / \mathrm{S})$ before cooling start. This mass gain corresponds to the oxygen atoms which came on surface to be combined with the most oxidable element present in the alloy: $\mathrm{Cr}$. This can be expressed by the following equations:

$\frac{d\left(\frac{\Delta m}{S}\right)}{d t}=\frac{M_{o}}{S} \times\left(\frac{d n_{o}}{d t}\right)$

with $\Delta m$ being the mass gain at the instant $\mathrm{t}, S$ the total surface of the sample (and then $\frac{d\left(\frac{\Delta m}{S}\right)}{d t}$ isoth end the rate of mass gain per surface unit area at the end of the isothermal 
stage), $M_{o}$ the molar mass of oxygen $\left(16 \mathrm{~g} \times \mathrm{mol}^{-1}\right)$ and $\left(\frac{d n_{o}}{d t}\right)_{\text {isoth end }}$ the number of oxygen moles coming from gas to be combined with metal and then to join the oxide scale covering the sample.

In such chromium-rich alloy it can be supposed that oxidation only concerns chromium. Thus the oxidation reaction is principally:

$$
2 \times \mathrm{Cr}+\frac{3}{2} \mathrm{O}_{2} \rightarrow \mathrm{Cr}_{2} \mathrm{O}_{3}
$$

and then:

$$
\left(\frac{d n_{C r}}{d t}\right)_{\text {isoth end }}=\frac{2}{3} \times\left(\frac{d n_{O}}{d t}\right)_{\text {isoth end }}
$$

where $\left(\frac{d n_{C r}}{d t}\right)_{\text {isoth end }}$ is the number of chromium moles coming from the alloy to be combined with oxygen and to join the oxide scale covering the sample.

Finally:

$$
\left(\frac{d n_{C r}}{d t}\right)_{\text {isoth end }}=\left(\frac{2 \times S}{3 \times M_{o}}\right) \times \frac{d\left(\frac{\Delta m}{S}\right)}{d t \quad \text { isoth end }}
$$

\subsection{Characterization of the oxidized samples}

After return to room temperature the oxidized samples were first subjected to $\mathrm{X}$ ray diffraction, using a Philips X'Pert Pro diffractometer ( $\lambda=1.5406$ Angström, $\mathrm{Cu} \mathrm{K} \alpha)$ to specify the nature of the oxides formed on surface. They were thereafter covered by a thin layer of gold deposited by cathodic evaporation. This allowed examining the oxide scale by electron microscopy to characterize a second time the nature of the oxides. These ones were thus observed using a Scanning Electron Microscope (SEM) JEOL JSM 6010LA in Secondary Electrons (SE) mode and analysed by Energy Dispersion Spectrometry (EDS).

The electrical conductivity given to the oxidized samples by gold deposition allowed electrolytically coating them with a thick layer of nickel (polarized as cathode in a $50^{\circ} \mathrm{C}$-heated Watt's bath). The samples were thereafter cut in two parts using a Buehler Delta Abrasimet saw, with minimized loss of the oxides now mechanically 
protected by the nickel coating. The two parts of each oxidized sample were embedded in a cold resin mixture (Araldite CY230 resin \& HY956 hardener, from Escil) and ground with $\mathrm{SiC}$ papers from 240-grit to 1200-grit. After ultrasonic cleaning these mounted samples were polished with textile enriched with $1 \mu \mathrm{m}$ hard particles.

The samples were then observed in cross-section with the SEM in Back Scattered Electrons (BSE) mode. EDS spot analysis was carried out to specify again the oxides' natures and also to get concentration profiles in the alloys' sub-surfaces, perpendicularly to the alloy/oxide interface.

The new distribution of chromium was then specified, revealing a subsurface zone impoverished in this element. The chromium profile presented an almost linear shape over the chromium-depleted depth, allowing the determination of an average value of the gradient of the chromium concentration (expressed in $\mathrm{mol} \times \mathrm{cm}^{-3}$ ): (thus in $\mathrm{mol} \times$ $\mathrm{cm}^{-4}$ ). This one can be written as following:

$$
\overrightarrow{\left\|\operatorname{grad} C_{C r}\right\|}=\frac{\rho}{M_{C r}} \times \frac{\Delta W_{C r}}{\Delta z}
$$

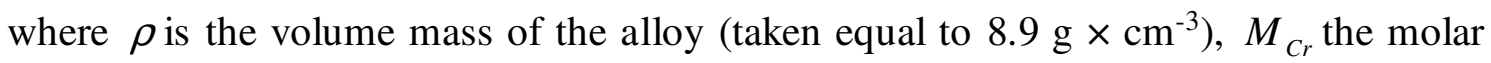
mass of chromium $\left(52 \mathrm{~g} \times \mathrm{mol}^{-1}\right)$ and $\frac{\Delta W_{C r}}{\Delta z}$ the average gradient of the weight content in chromium (z: depth).

\subsection{Determination of the average diffusion coefficient for chromium}

The data previously acquired were thereafter used to deduce the values of the average coefficients characterizing the chromium diffusion through the sub-surface, by writing and exploiting the Fick's first law:

$$
\left(\frac{d n_{C r}}{d t}\right)_{\text {isoth end }}=-D_{C r} \times \overrightarrow{\left\|\operatorname{grad} C_{C r}\right\|}
$$

By replacing $\left(\frac{d n_{C r}}{d t}\right)_{\text {isoth end }}$ and $\overline{\left\|\operatorname{grad} C_{C r}\right\|}$ by $\left(\frac{2 \times S}{3 \times M_{o}}\right) \times \frac{d\left(\frac{\Delta m}{S}\right)}{d t}$ isoth end and $\frac{\rho}{M_{C r}} \times \frac{\Delta W_{C r}}{\Delta z}$ respectively one can express $D_{C r}$ as follows: 


$$
D_{C r}=\left(\frac{2 \times M_{C r}}{3 \times M_{O}}\right) \times \frac{\frac{d\left(\frac{\Delta m}{S}\right)}{d t} \text { isoth end }}{\rho \times \frac{\Delta W_{C r}}{\Delta z}}+K_{v}
$$

where $K_{v}$ is a constant, depending on temperature, characterizing the linear loss of chromia $\mathrm{Cr}_{2} \mathrm{O}_{3}$ by over-oxidation into volatile $\mathrm{CrO}_{3}$ when temperature is higher than $1000^{\circ} \mathrm{C}$. This constant was determined for all thermogravimetry tests by applying a method of treatment of the mass gain files extensively described in an earlier work [13]. To summarize this consists in plotting the mass gain files in the scheme $\frac{\Delta m}{S} \times \frac{d\left(\frac{\Delta m}{S}\right)}{d t}=f\left(-\frac{\Delta m}{S}\right)$ and by deducing, from the linear part of the obtained new curve, the $K_{v}$ value which is simply its slope.

\subsection{Thermodynamic calculations}

To finish, to interpret some particular microstructural phenomena occurred in the sub-surface which consequences for the origin of a part of chromium diffusing toward the oxidation front during the tests some thermodynamic calculations were carried out with the Thermo-Calc software (N version) [14] working with a database containing the descriptions of the Ni-Cr-C system and its subsystems [15-16].

\section{Results}

\subsection{The obtained mass gain curves}

The three obtained mass gain curves are plotted together in Fig. 1. They are all parabolic-shaped, this revealing that the external oxide formed is continuous all around the samples when the isothermal stage starts. The oxidation rate is thus controlled by the diffusion of the species involved in the oxidation phenomena through this oxide scale. The mass gain is faster for a higher temperature but all these rates are rather slow (Table 1) by considering the test temperature (only $0.42,1.07$ and $1.31 \mathrm{mg} / \mathrm{cm}^{2}$ after 46 hours at respectively 1000,1050 and $1100^{\circ} \mathrm{C}$ ), this suggesting that the oxide formed is essentially the protective chromia $\left(\mathrm{Cr}_{2} \mathrm{O}_{3}\right)$ one. 
The final mass gain rates (at the end of the isothermal part were determined (example in Fig. 2) and their values are presented in Table 1. The linear constants $\mathrm{K}_{\mathrm{v}}$ representing the mass loss rate due to the volatilization of chromia were determined by plotting $\frac{d\left(\frac{\Delta m}{S}\right)}{d t}$ versus $-\frac{\Delta m}{S}$ (illustrated ion Fig. 3) and the obtained values are given in Table 1 too.

\subsection{Post-mortem characterization of the oxidized samples}

The nature of the external oxide scale was specified by the X-ray diffractograms performed on one of the two main faces before cutting of the oxidized samples. As illustrated by the diffractogram presented in Fig. 4, chromia is well present over the samples. Even if it is not the single oxide present $\mathrm{Cr}_{2} \mathrm{O}_{3}$ is by far the predominantly one. The surface states as observed with the SEM at different magnifications for the two modes SE (Secondary Electrons) and BSE (Back Scattered Electrons) are illustrated in Fig. 5 in which some results of EDS (Energy Dispersion Spectrometry) are added for identifying the oxides. One can see again that chromium is the most present oxide despite the presence of minor oxides $\left(\mathrm{NiCr}_{2} \mathrm{O}_{4}, \mathrm{NiO}\right)$ was also detected. One can also notice that parts of the external oxide were obviously lost by oxide spallation during the cooling.

After cutting, embedding and grinding/polishing the oxidized samples were observed in cross-section with the SEM in BSE mode and concentration profiles were acquired in the sub-surface affected by oxidation by spot EDS analysis. The obtained chromium concentration profiles are presented together by a SEM/BSE micrograph of the analysed zone, in Fig. 6 for the sample oxidized at $1000^{\circ} \mathrm{C}$, Fig. 7 for the one oxidized at $1050^{\circ} \mathrm{C}$ and Fig. 8 for the one oxidized at $1100^{\circ} \mathrm{C}$. The chromium content increases from about $15 \mathrm{wt} . \%$ to $20 \mathrm{wt} . \%$ (respectively $17 \mathrm{wt} . \%$ to $22 \mathrm{wt} . \%$ and $18 \mathrm{wt} . \%$ to $22 \mathrm{wt} . \%$ ) over $10 \mu \mathrm{m}$ (resp. $20 \mu \mathrm{m}$ and $30 \mu \mathrm{m}$ ) in the sub-surface of the sample oxidized at $1000^{\circ} \mathrm{C}$ (resp. $1050^{\circ} \mathrm{C}$ and $1100^{\circ} \mathrm{C}$ ). The chromium gradients, slopes of the regression straight lines, are given in Table 2. 


\subsection{The obtained diffusion coefficients of chromium}

The same Table 2 also presents the average diffusion coefficients deduced from the final isothermal mass gain rates, chromia volatilization constants and these chromium concentration gradients according to the following equation:

$$
D_{C r}=\left(\frac{2 \times M_{C r}}{3 \times M_{O}}\right) \times \frac{\frac{d\left(\frac{\Delta m}{S}\right)}{d t} \text { isoth end }_{v}+K_{v}}{\rho \times \frac{\Delta W_{C r}}{\Delta z}}
$$

The chromium coefficient of chromium through the carbide-free zone of the subsurface, to which corresponds more or less the Cr-depleted zone, logically increases with temperature. Furthermore it obviously obeys an Arrhenius law, as demonstrated by the graph displayed in Fig. 9, with $466 \mathrm{~kJ} / \mathrm{mol}$ as activation energy.

\section{Discussion}

The conditions of determination of the chromium diffusion coefficients were very favourable in this work. Indeed, first the oxidation kinetics were of the parabolic type and the mass gain curves were not affected by significant irregularities. They were no affected by any jumps in mass gain as this often occurred, and the final mass gain rate measured at the end of the isothermal stages was representative of the whole surface around the samples. The location of determination of the chromium gradient can be chosen everywhere around the cross-section since, consequently, no heterogeneity was feared. Otherwise, thanks to the fact that the study's alloy was a nickel-based one, in addition with the presence of a rather high chromium weight content, the behaviour of the alloy was chromia-forming at the three temperatures, even if small quantities of nickel oxide $(\mathrm{NiO})$ and spinel oxide $\left(\mathrm{NiCr}_{2} \mathrm{O}_{4}\right)$ were also present in addition to the major $\mathrm{Cr}_{2} \mathrm{O}_{3}$ oxide (which is paradoxically often the case for chromia-forming nickelbased alloys) as revealed by small peaks in the XRD diffractograms and by EDS on the oxide scale. Thanks to their low quantities these supplementary did not cause problem. The cooling was accompanied by the loss of a part of this external oxide scale by spallation, but this without any consequence for the chromium distribution in subsurface. The post-treatment of the mass gain files also allowed determining the values of volatilization constants. This phenomenon must be taken into account and its 
kinetic valued since the linear mass loss was of the same order of magnitude as the final value of isothermal mass gain rate.

The Cr-depleted subsurface zones over which the gradient in chromium weight content were specified globally corresponded to the external zone of alloy were carbides have disappeared, the depth of which increased with the isothermal temperature for the given duration of 46 hours. In one case out of the three ones $\left(1000^{\circ} \mathrm{C}\right)$ new carbides precipitated in the matrix of all the bulk, by usual secondary precipitation during stage at this temperature for such alloys. By taking into account the almost linear profile in chromium existing over these carbide-free zones thermodynamic calculations carried out with Thermo-Calc clearly showed that the local level in carbon was necessarily very low, as illustrated in Fig. 10 by the isothermal sections of the $\mathrm{Ni}$ $\mathrm{Cr}-\mathrm{C}$ diagram computed here. Thus one can think that no carbon may influence the diffusion coefficients of chromium which were determined here.

The obtained values of the chromium diffusion coefficient assessed here for these three temperatures, are higher when the isothermal stage temperature was higher. They are close to results earlier determined for the same temperatures in other nickel alloys with neighbour chemical compositions. They are more suitable for interpretation of oxidation behaviour since they include the participation of interdendritic spaces having lost their initial carbides, what usually occurs for chromium carbides-containing alloys. Furthermore it well follows an Arrhenius law for which an accurate value of activation energy was thus determined.

Unfortunately the method used here cannot be really applied in some cases for cobalt-based alloys the oxidation which is more rarely almost completely chromiaforming (presence of more spinel $\mathrm{CoCr}_{2} \mathrm{O}_{4}$ ) and for iron-based alloys for which the $\mathrm{M}_{2} \mathrm{O}_{3}$ is not $\mathrm{Cr}_{2} \mathrm{O}_{3}$ but $(\mathrm{Cr}, \mathrm{Fe})_{2} \mathrm{O}_{3}$ with various amounts in $\mathrm{Fe}$.

\section{Conclusion}

The thermogravimetry tests - usually devoted to the determination of the oxidation rates - combined with the chromium concentration profiles - generally acquired to specify the $\mathrm{Cr}$-depleted zones and the minimal $\mathrm{Cr}$ content in extreme surface - can be thus combined to estimate diffusion coefficients. The values obtained here, in rather good agreement with ones previously established, show that this technique is 
efficient. Furthermore it gives diffusion coefficients which are closer to the reality of the oxidation at high temperature since, this determination being done directly by taking into account the local modifications induced by the first times of oxidation (disappearance of carbides, new distribution of carbon...), the obtained values closely concern the subsurface where the $\mathrm{Cr}$ diffusion is of great importance for the sustainability of the chromia-forming behavior.

\section{Acknowledgements}

The authors thank Thierry Schweitzer who carefully prepared the samples for the oxidation tests and Pascal Villeger who performed the XRD analyses.

\section{References}

[1] I. S. Kiva, N. G. Kaidash, Diffusion Parameters of Metal and Alloys, Soviet Powder Metallurgy and Metal Ceramics 7(8) (1968) 635-637.

[2] P. Duwez, The Formation of Alloys by Diffusion in Powder Metallurgy, Powder Met. Bull. 4 (1949) 144-156.

[3] M. A. Shtremel, Participation of Diffusion in the Processes of Mechanical Alloying, Metal Science and Heat Treatment 44(7-8) (2002) 324-327.

[4] B. Clausen, K. A. Thorsen, Joining of Iron-based P/M Components by Brazing and Diffusion Bonding, Advances in Powder Metallurgy \& Particulate Materials 4 (1992) 191-207.

[5] H. J. Christ, W. Christ, H. G. Sockel, Carburization of High-Temperature Materials - Part I; Mathematical Model of the Penetration and Simultaneous Precipitation of a Compound of the Diffusing Element, Werkstoffe und Korrosion 37(7) (1986) 385-390.

[6] H. Inoue, K. Asao, M. Ishio, T. Takasugi, Texture Evolution during Diffusional Heat Treatment from Roll-Bonded Ti/Ni Laminates to TiNi Shape Memory Alloy Sheets, Materials Science Forum, 534-543 (2007) 3442-3447.

[7] P. Kofstad, High Temperature Corrosion, Elsevier applied science, London, 1988.

[8] D. Young, High Temperature Oxidation and Corrosion of Metals, Elsevier Corrosion Series, Amsterdam, 2008.

[9] C.T. Sims, W.C. Hagel, The Superalloys, John Wiley \& Sons, New York, 1972. 
[10] E. F. Bradley, Superalloys: A Technical Guide, ASM International, Metals Park, 1988.

[11] P. Berthod, Influence of Chromium Carbides on the High Temperature Oxidation Behavior and on Chromium Diffusion in Nickel-Base Alloys, Oxidation of Metals, 68 (2007) 77-96.

[12] P. Berthod, S. Noël, L. Aranda, Influence de l'Orientation Dendritique sur le Cinétique d'Oxydation à Haute Température d'Alliages de Nickel contenant des Carbures, Annales de Chimie - Science des Matériaux 33(1) (2008) 59-80.

[13] P. Berthod, Kinetics of High Temperature Oxidation and Chromia Volatilization for a Binary Ni-Cr Alloy, Oxidation of Metals 64(3/4) (2005) 235-252.

[14] Thermo-Calc version N: "Foundation for Computational Thermodynamics" Stockholm, Sweden, Copyright (1993, 2000). www.thermocalc.com

[15] J.-O. Andersson, Thermodynamic properties of chromium-carbon, Calphad 11(3) (1987) 271-276.

[16] A. Gabriel, C. Chatillon, I. Ansara, Thermochemical and Phase Diagram Analysis of the Nickel-Carbon, Cobalt-Carbon, and Cobalt-Nickel-Carbon Systems, High Temperature Science 25(1) (1988) 17-54. 
Table 1

Values of the total isothermal mass gains and of the final mass gain rates at the end of the isothermal stages

\begin{tabular}{|c|c|c|c|}
\hline Test temperature & $1000^{\circ} \mathrm{C}$ & $1050^{\circ} \mathrm{C}$ & $1100^{\circ} \mathrm{C}$ \\
\hline $\begin{array}{l}\text { Total isothermal mass } \\
\text { gain } \\
\left(\mathrm{mg} \times \mathrm{cm}^{-2}\right)\end{array}$ & 0.72 & 1.07 & 1.31 \\
\hline $\begin{array}{l}\text { Final mass gain rates } \\
\left(\times 10^{-10}{\left.\mathrm{~g} \times \mathrm{cm}^{-2} \times \mathrm{s}^{-1}\right)}\right.\end{array}$ & 10.0 & 22.1 & 30.2 \\
\hline $\begin{array}{l}\text { Volatilization constant } \\
K_{v} \\
\left(\times 10^{-10} \mathrm{~g} \times \mathrm{cm}^{-2} \times \mathrm{s}^{-1}\right)\end{array}$ & 15.2 & 30.7 & 46.3 \\
\hline
\end{tabular}

Table 2

Values of the gradient in chromium weight content and of the deduced diffusion coefficient of chromium; comparison with some literature data

\begin{tabular}{|c|c|c|c|}
\hline Test temperature & $1000^{\circ} \mathrm{C}$ & $1050^{\circ} \mathrm{C}$ & $1100^{\circ} \mathrm{C}$ \\
\hline $\begin{array}{c}\text { Cr gradient in subsurface } \\
\left(\text { wt. } \% \times \mu \mathrm{m}^{-1}\right)\end{array}$ & 0.702 & 0.277 & 0.072 \\
\hline$D_{C r}\left(\times 10^{-11} \mathrm{~cm}^{2} \mathrm{~s}^{-1}\right)$ & $1.1 \times 10^{-11} \mathrm{~cm}^{2} \mathrm{~s}^{-1}$ & $4.7 \times 10^{-11} \mathrm{~cm}^{2} \mathrm{~s}^{-1}$ & $26 \times 10^{-11} \mathrm{~cm}^{2} \mathrm{~s}^{-1}$ \\
\hline Literature data [17] & $1000^{\circ} \mathrm{C}$ & $1050^{\circ} \mathrm{C}$ & $1100^{\circ} \mathrm{C}$ \\
\hline Inconel & $1.5 \times 10^{-11} \mathrm{~cm}^{2} \mathrm{~s}^{-1}$ & $3.4 \times 10^{-11} \mathrm{~cm}^{2} \mathrm{~s}^{-1}$ & $10 \times 10^{-11} \mathrm{~cm}^{2} \mathrm{~s}^{-1}$ \\
\hline Literature data [18] & \multicolumn{2}{|c|}{$1025^{\circ} \mathrm{C}$} & $1150^{\circ} \mathrm{C}$ \\
\hline $\mathrm{Ni}-15.2 \mathrm{Cr}-7.8 \mathrm{Fe}+$ minor & \multicolumn{2}{|c|}{ / } & $20 \times 10^{-11} \mathrm{~cm}^{2} \mathrm{~s}^{-1}$ \\
\hline Ni-16.5Cr-7.4Fe +minor & \multicolumn{2}{|c|}{$0.8 \times 10^{-11} \mathrm{~cm}^{2} \mathrm{~s}^{-1}$} & $31 \times 10^{-11} \mathrm{~cm}^{2} \mathrm{~s}^{-1}$ \\
\hline $\mathrm{Ni}-16.2 \mathrm{Cr}-6.8 \mathrm{Fe}+$ minor & \multicolumn{2}{|c|}{$1.9 \times 10^{-11} \mathrm{~cm}^{2} \mathrm{~s}^{-1}$} & $43 \times 10^{-11} \mathrm{~cm}^{2} \mathrm{~s}^{-1}$ \\
\hline
\end{tabular}




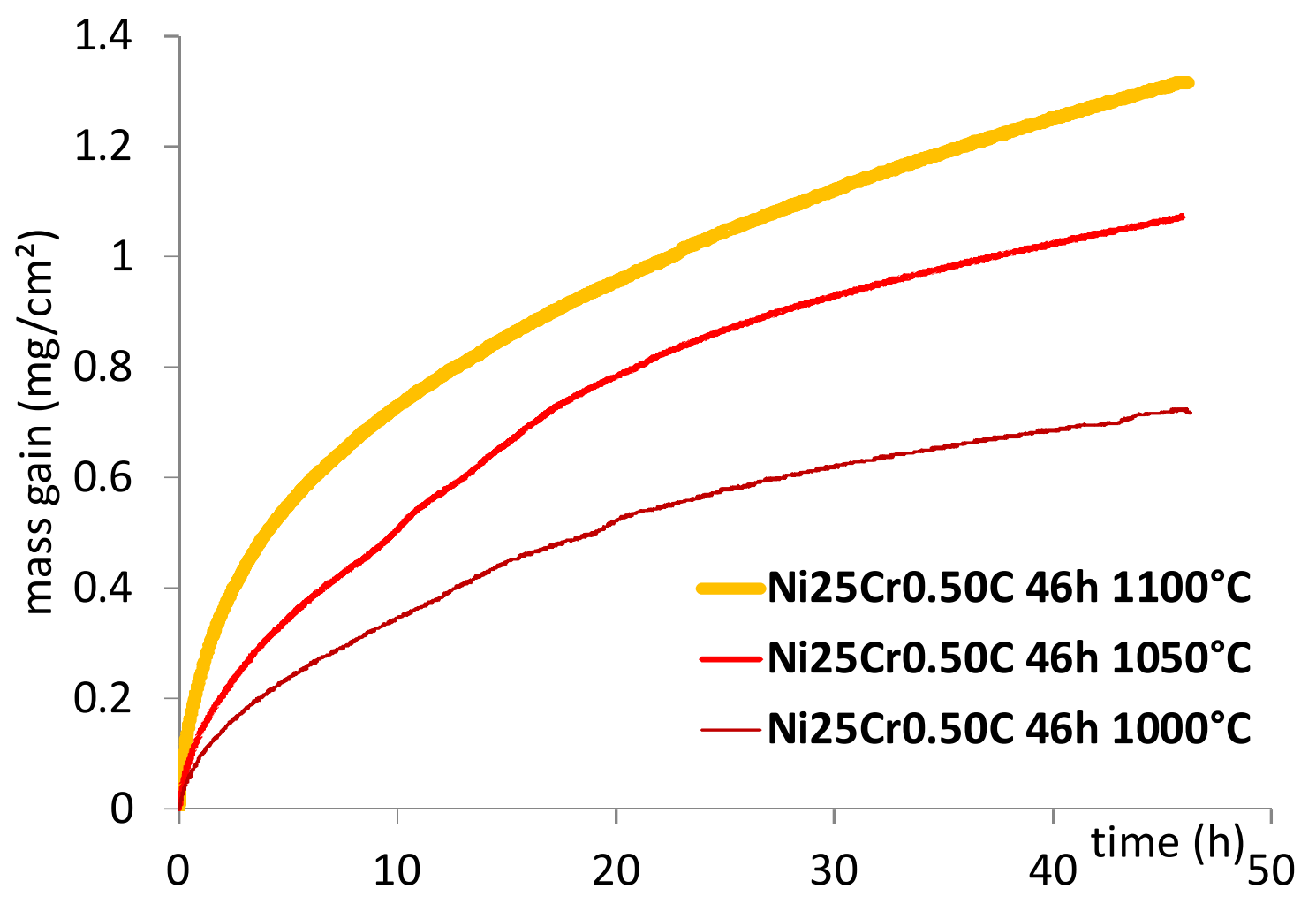

Fig. 1. The three mass gain curves obtained during oxidation of the Ni$25 \mathrm{Cr}-0.5 \mathrm{C}$ alloy at $1000^{\circ} \mathrm{C}, 1050^{\circ} \mathrm{C}$ and $1100^{\circ} \mathrm{C}$ for 46 hours 


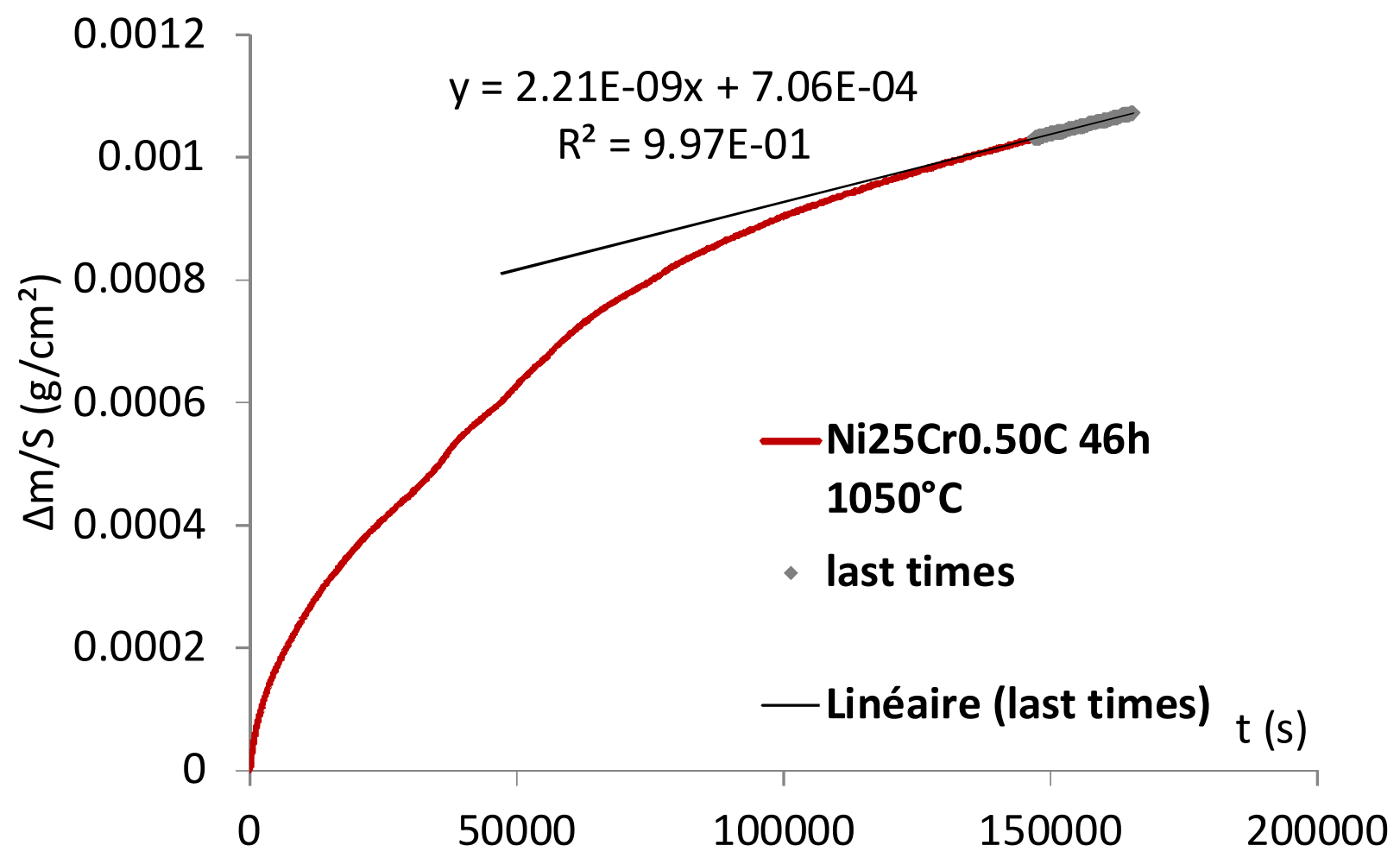

Fig. 2. Determination of the final mass gain rate at the end of the $46 \mathrm{~h}-$ long isothermal stage (here: test of the $\mathrm{Ni}-25 \mathrm{Cr}-0.5 \mathrm{C}$ alloy at $1050^{\circ} \mathrm{C}$ ) 


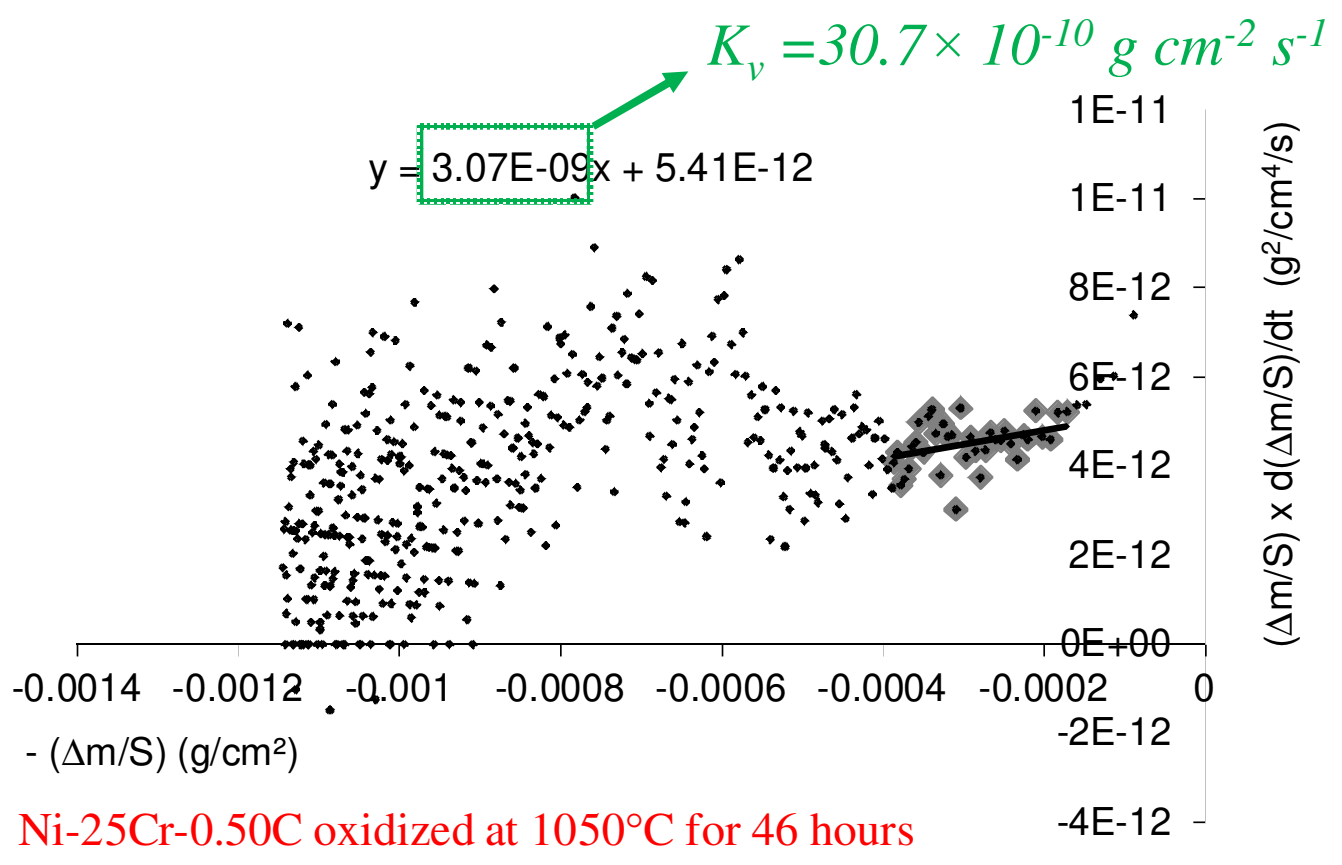

Fig. 3. Example of determination of the linear constant $K_{v}$ characterizing the mass loss rate by volatilization of chromia (here: test of the $\mathrm{Ni}-25 \mathrm{Cr}$ $0.5 \mathrm{C}$ alloy at $1050^{\circ} \mathrm{C}$ ) 


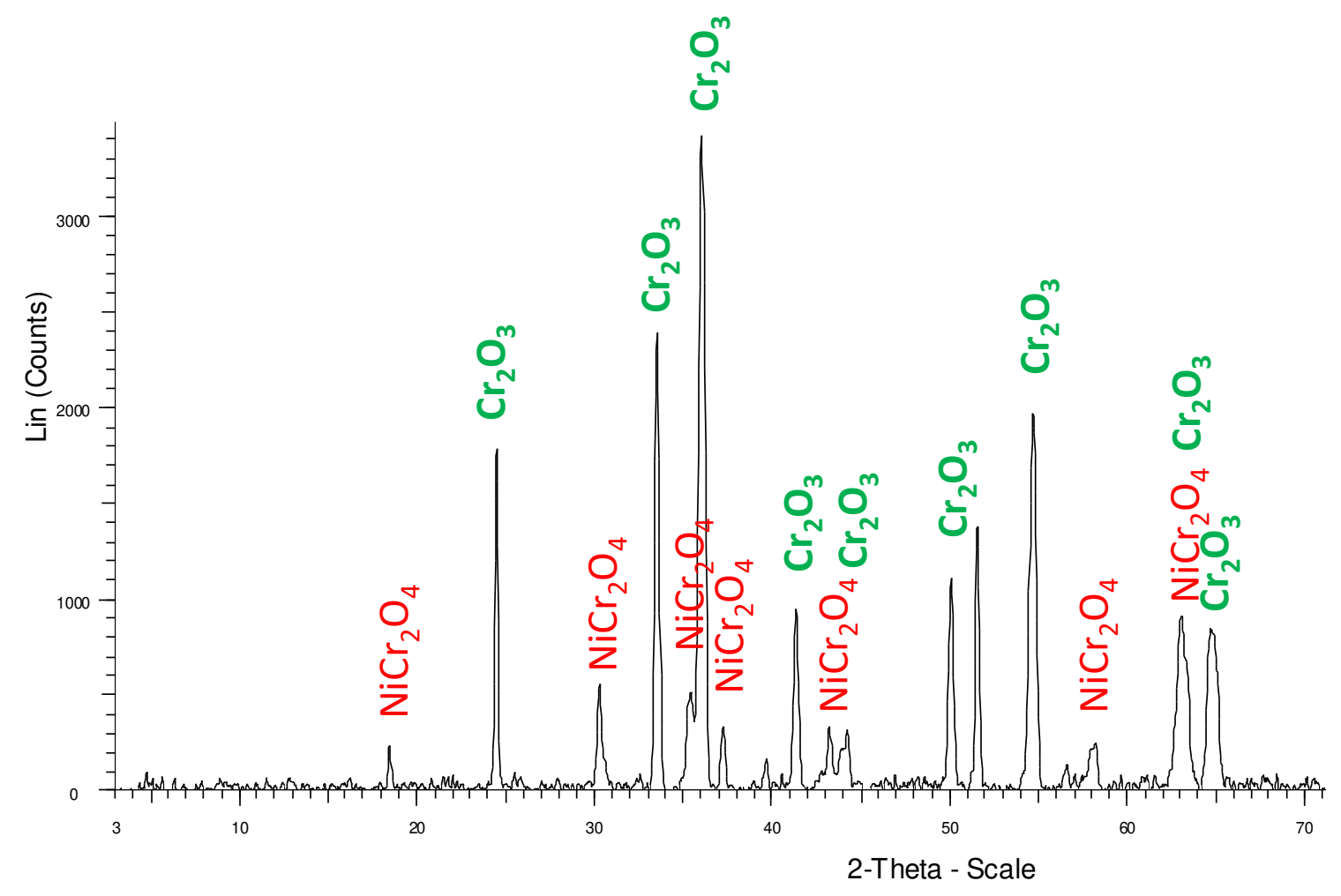

Fig. 4. X-ray diffractogram acquired on the oxidized surface of the Ni$25 \mathrm{Cr}-0.5 \mathrm{C}$ oxidized at $1050^{\circ} \mathrm{C}$ for 46 hours 

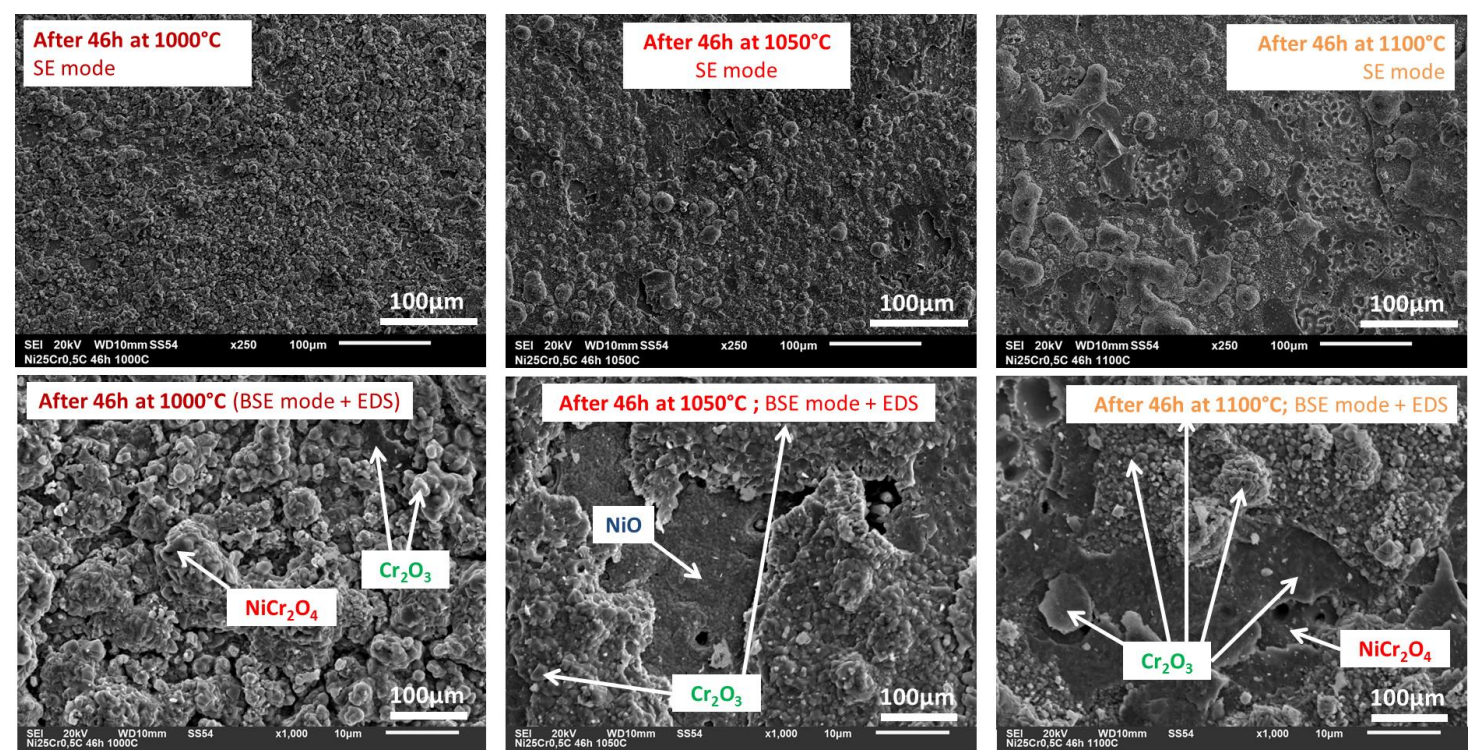

Fig. 5. SEM micrographs of the oxide scales at two magnifications and for two modes of electronic observation (top: SE and bottom: BSE) illustrating the surface states after 46 hours of oxidation at $1000^{\circ} \mathrm{C}$ (left), $1050^{\circ} \mathrm{C}$ (middle) and $1100^{\circ} \mathrm{C}$ (right), with identification of the different oxides by EDS spot measurement (bottom) 


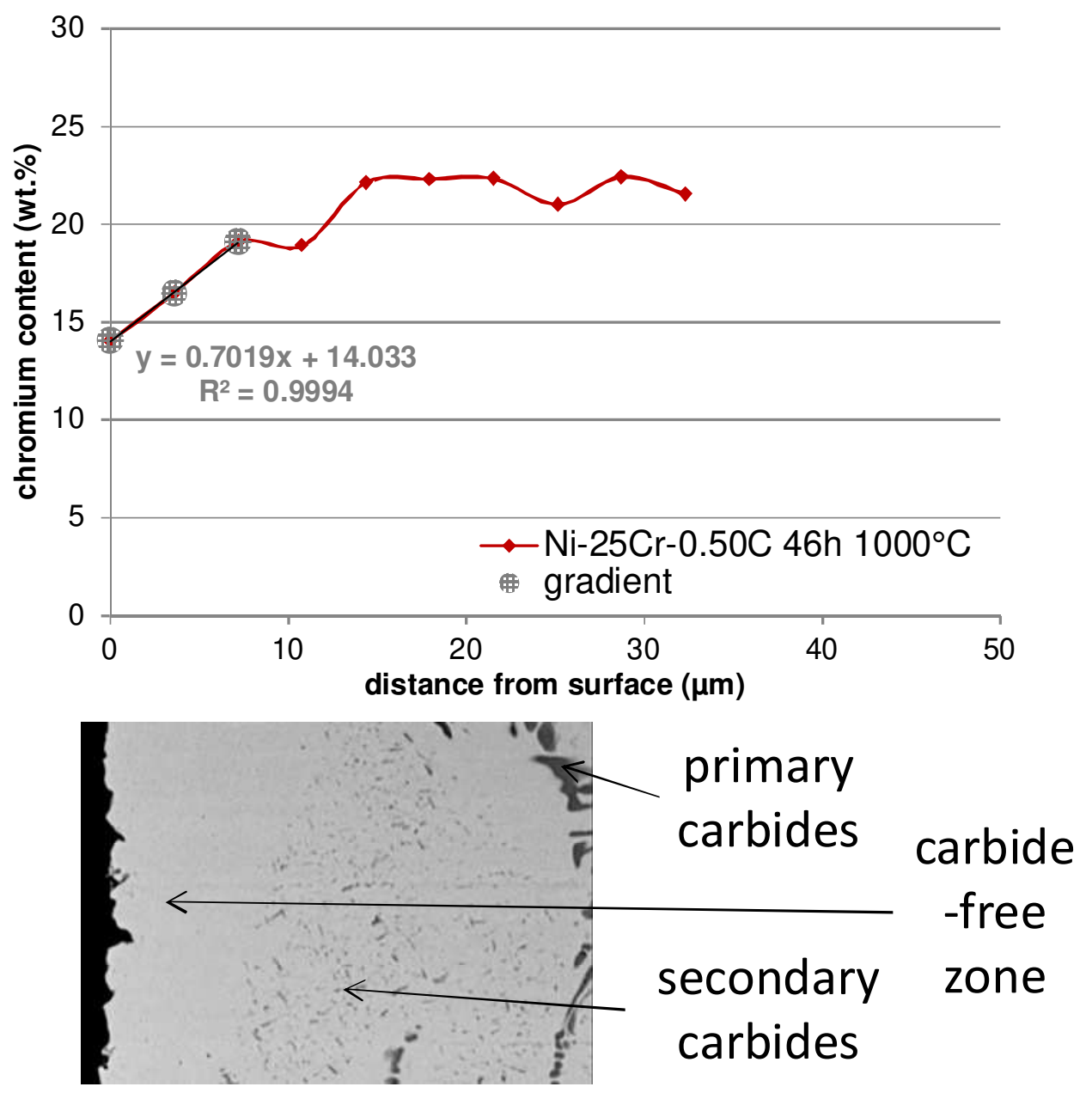

Fig. 6. Chromium profile and concentration gradient in chromium through the $\mathrm{Cr}$-depleted sub-surface zone of the sample oxidized at $1000^{\circ} \mathrm{C}$; corresponding SEM/BSE micrograph of the concerned zone (same scale as the $\mathrm{x}$-axis of the graph) 

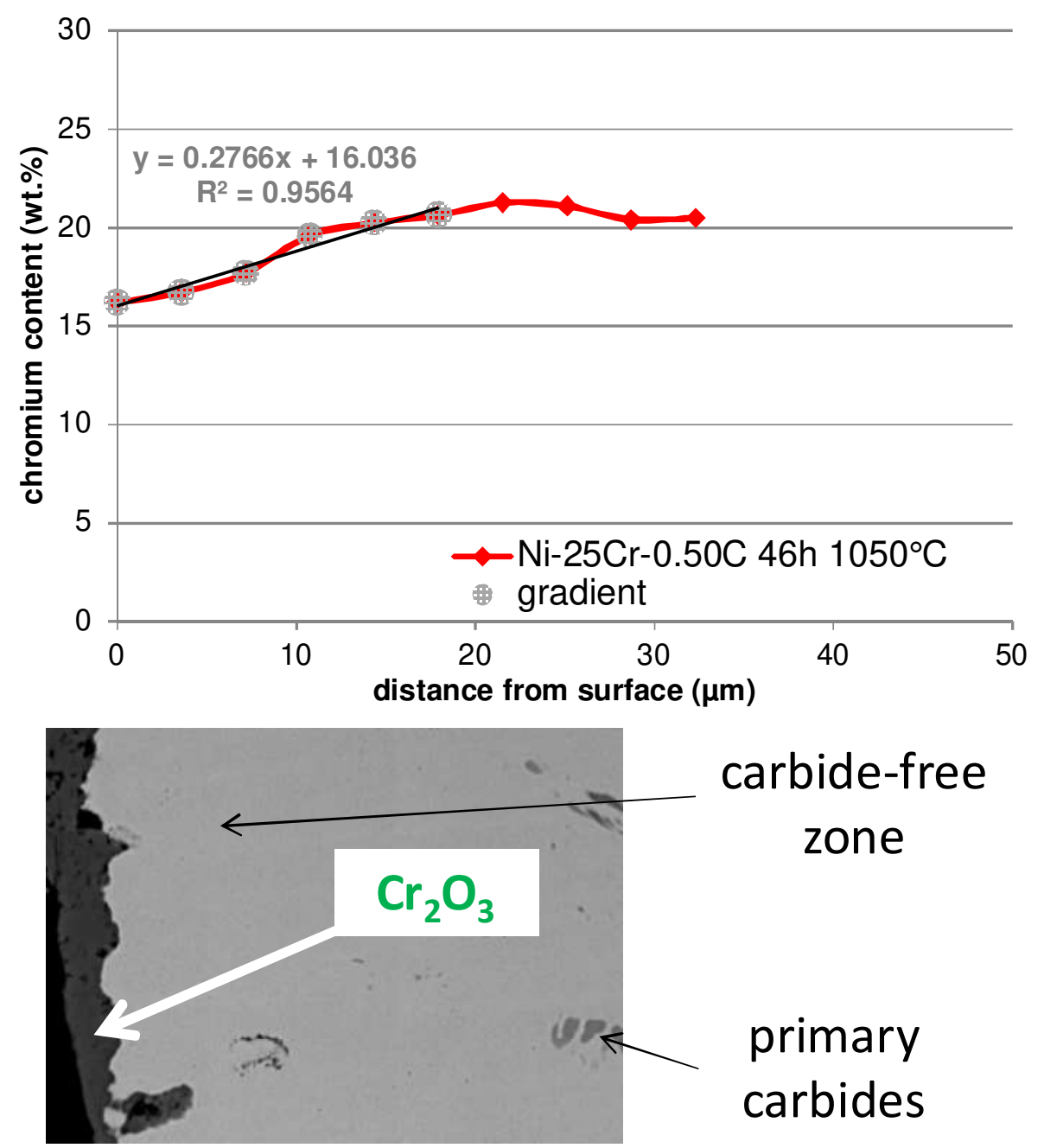

carbide-free zone primary carbides

Fig. 7. Chromium profile and concentration gradient in chromium through the Cr-depleted sub-surface zone of the sample oxidized at $1050^{\circ} \mathrm{C}$; corresponding SEM/BSE micrograph of the concerned zone (same scale as the $\mathrm{x}$-axis of the graph) 


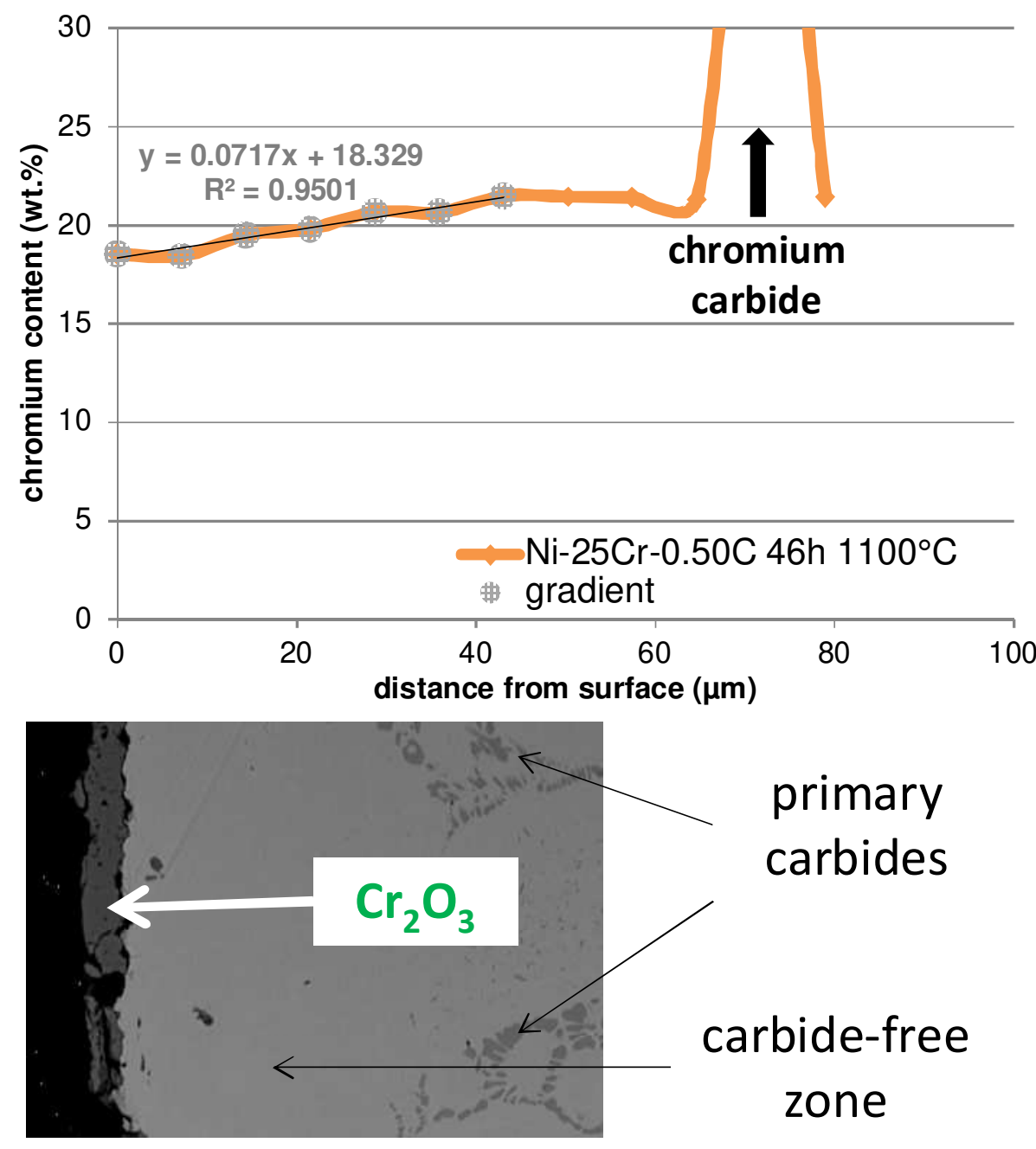

Fig. 8. Chromium profile and concentration gradient in chromium through the Cr-depleted sub-surface zone of the sample oxidized at $1100^{\circ} \mathrm{C}$; corresponding SEM/BSE micrograph of the concerned zone (same scale as the $\mathrm{x}$-axis of the graph) 


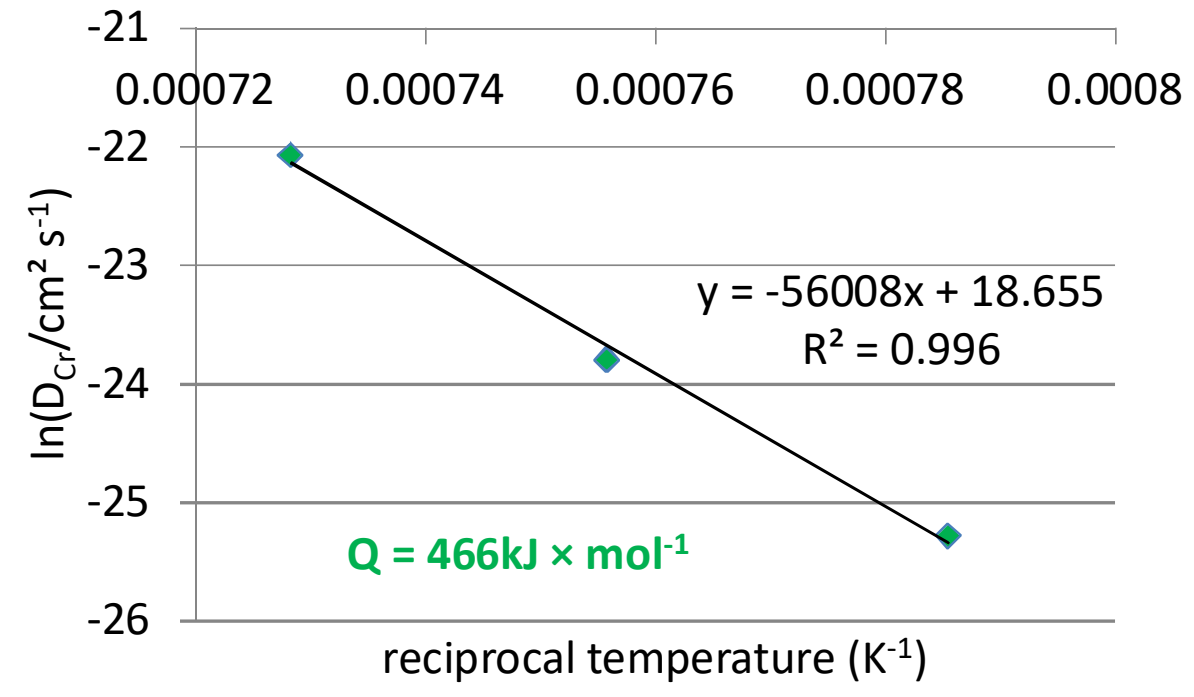

Fig. 9. Arrhenius plot of the determined values of $\mathrm{Cr}$ diffusion coefficients 

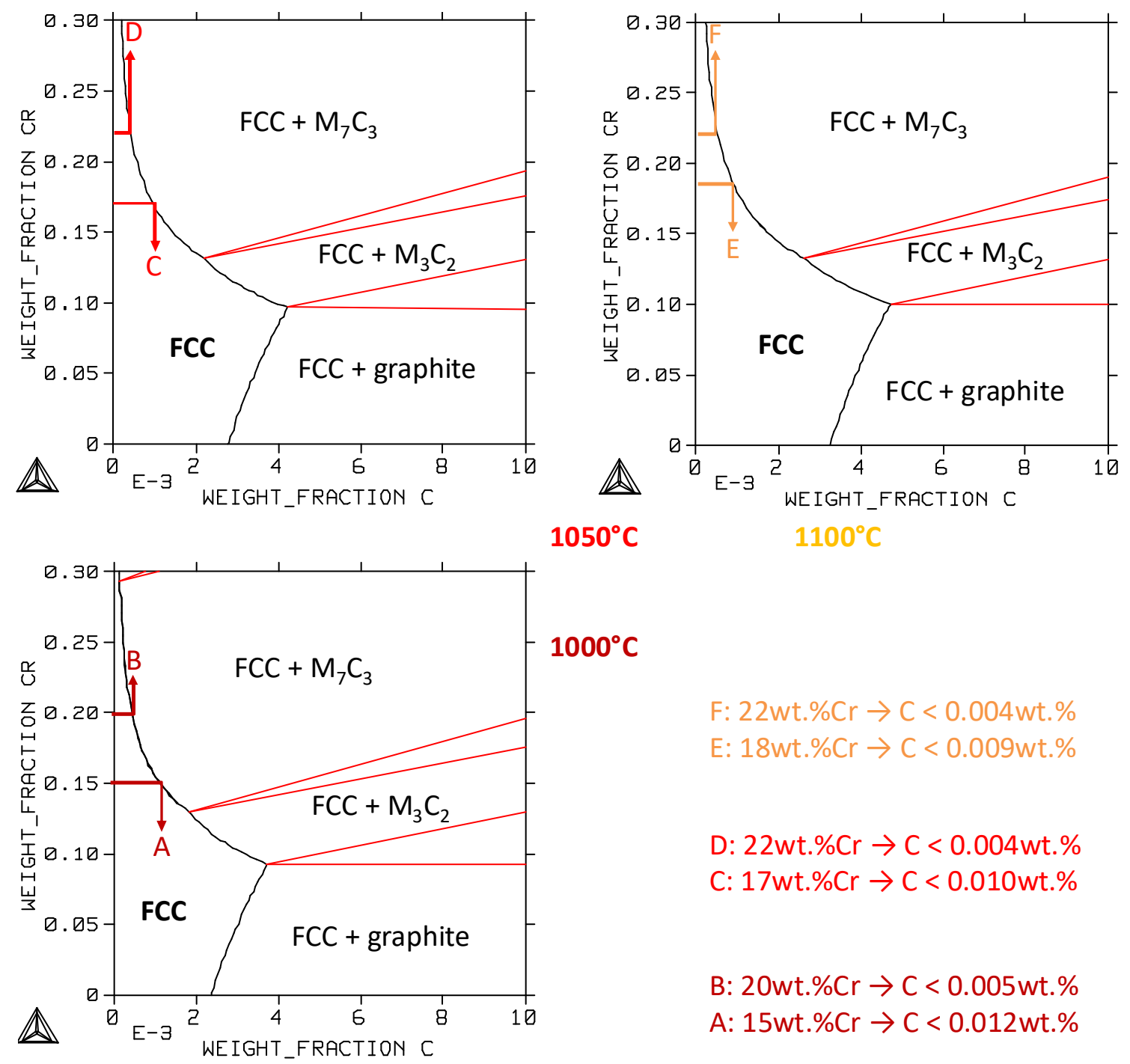

F: $22 w t . \% C r \rightarrow C<0.004 w t . \%$

E: $18 w t . \% C r \rightarrow C<0.009 w t . \%$

D: $22 \mathrm{wt} . \% \mathrm{Cr} \rightarrow \mathrm{C}<0.004 \mathrm{wt} . \%$

C: $17 w t . \% C r \rightarrow$ C $<0.010 w t . \%$

B: $20 w t . \% C r \rightarrow C<0.005 w t . \%$

A: $15 w t . \% C r \rightarrow C<0.012 w t . \%$

Fig. 10. Isothermal phase diagrams computed with Thermo-Calc for $1000^{\circ} \mathrm{C}, 1050^{\circ} \mathrm{C}$ and $1100^{\circ} \mathrm{C}$, evidencing that the carbon contents are necessarily much lower than initially in the carbide-free zones 